\title{
Kernos
}

Revue internationale et pluridisciplinaire de religion grecque antique

$14 \mid 2001$

Varia

\section{BRISSON, Platon 1990-1995 : bibliographie}

\section{André Motte}

\section{(2) OpenEdition}

\section{Journals}

Édition électronique

URL : http://journals.openedition.org/kernos/794

DOI : $10.4000 /$ kernos.794

ISSN : 2034-7871

Éditeur

Centre international d'étude de la religion grecque antique

Édition imprimée

Date de publication : 1 janvier 2001

Pagination : 322

ISSN : 0776-3824

Référence électronique

André Motte, «L. BRIsson, Platon 1990-1995 : bibliographie », Kernos [En ligne], 14 | 2001, mis en ligne le 14 avril 2011, consulté le 24 septembre 2020. URL : http://journals.openedition.org/kernos/794 ; DOI : https://doi.org/10.4000/kernos.794 
Luc Brisson, Platon 1990-1995: bibliograpbie, avec la collaboration de Fr. Plin, Paris, Vrin, 1999. 1 vol. $13,5 \times 21 \mathrm{~cm}, 416$ p. ISBN : 2-7116-1412-3.

Les platonisants connaissent bien cette remarquable bibliographie périodique qui leur rend les plus grands services et qui, commencée en 1950, a paru jusqu'en 1990 dans la revue Lustrum. Mais l'importance des mentions religieuses dont regorgent les dialogues de Platon est telle qu'il n'est pas inutile de recommander aussi ce répertoire aux spécialistes de la religion grecque. Quelque 1800 études (ouvrages ou articles) portant sur ce philosophe, sans compter les travaux d'édition et de traduction, sont ici soigneusement répertoriées. Dans ce corpus, présenté dans l'ordre alphabétique des auteurs, les références sont souvent accompagnées d'une notice analytique et sont pourvues d'un numéro d'ordre permettant les renvois. C'est qu'en fin de volume, un index thématique dresse le panorama détaillé des matières traitées et renvoie, pour chacune d'entre elles, aux numéros concernés du corpus. Une trentaine d'études sont ainsi reprises sous la rubrique "Mythe et allégorie » (p. 393) et presque autant sous la rubrique « Religion, théologie » (p. 398). Si on s'intéresse à la pensée religieuse, on songera aussi à consulter d'autres rubriques, comme celles qui sont relatives à l'âme, à ses "folies » et à son immortalité, à la vertu de piété, etc. Cet index est si clairement conçu qu'on n'a aucune peine à y déceler les sujets auxquels on s'intéresse. À signaler encore, parmi d'autres outils, un index abondant des mots grecs, comportant également des renvois aux études concernées du corpus. Voilà une bibliographie qui est, à bien des égards, un modèle du genre.

André Motte (Université de Liège)

Papyri Bodmer XXX-XXXVII. "Codex des Visions". Poèmes divers, éd. avec une introduction générale, des traductions et des notes par André Hurst et Jean Rudhard, München, K.G. Saur, 1999. 1 vol. $15,5 \times 24 \mathrm{~cm}$, $\mathrm{vI}+226$ p. (Bibliotheca Bodmeriana. Fondation Martin Bodmer ColognyGenève). ISBN : 3-598-22554-7.

La collection de papyrus, païens et chrétiens, de la Fondation Martin Bodmer à Cologny-Genève continue à révéler ses trésors cachés. De nombreuses années ont passé depuis la publication des chants V et VI de l'Iliade ${ }^{1}$, du Dyscolos de Ménandre $^{2}$ et du Protévangile de Jacques ${ }^{3}$. D'autres textes ont été découverts et publiés entretemps, tandis que d'autres attendent encore d'être lus et interprétés ${ }^{4}$. Avec la publication de ce volume splendide se termine aujourd'hui l'editio princeps du Codex des Visions. La célèbre Vision de Dorothéos a déjà vu le jour en

1 V. Martin, Papyrus Bodmer I, Iliade, chants 5 et 6, Cologny/Genève, 1954.

2 V. Martin, Papyrus Bodmer IV, Ménandre: Le Dyscolos, Cologny/Genève, 1958.

3 M. Testuz, Papyrus Bodmer V, Nativité de Marie, Cologny/Genève, 1958, suivi par la nouvelle édition de É. De STRYCKer, La forme la plus ancienne du Protévangile de Jacques. Recherches sur le papyrus Bodmer 5 avec une édition critique du texte grec et une traduction annotée, Bruxelles, 1961 (Subsidia Hagiographica, 33).

4 Pour une présentation de la découverte, de l'origine et du contenu de la collection on peut se reporter à J.M. Robinson, The Pachomian Monastic Library at the Chester Beatty Library and the Bibliothèque Bodmer, Claremont CA, 1990 (Occasional Papers of the Institute for Antiquity and Cbristianity,19). 